\title{
RESENA
}

\section{Un ensayo para una novela: Guirnaldas (Bajo tierra), de Rodolfo Arias: De la novela al discurso de la Academia Costarricense de la Lengua Española}

Por: M.L. Dimitri Shiltagh Prada ${ }^{1}$, Instituto Tecnológico de Costa Rica, Costa Rica Fecha de recibido: $\quad 23$ de mayo, 2016. Fecha de aceptación: 17 de agosto, 2016.

He pensado ensayar sobre Guirnaldas (Bajo tierra) (2013) una de las mejores novelas costarricenses que he leído en los últimos diez años. ¡Menuda tarea, un ensayo una novela de Rodolfo Arias! Pues entonces he de hacerlo a fuerza de no caer en un artículo literario como traición filológica.

En primera instancia me referiré a este nombre, pues es un justo título para una novela que se construye sobre la metáfora y el lenguaje que Arias Formoso sabe colegir, y no sobre flores y ramas, más bien sobre efectos y causas. No hay en esta un solo detalle suelto, no hay azar en el acontecimiento, pero fortuna y juego son esenciales en su constitución. ¿Por qué el ajedrez?

Según se explica bajo el título "Metáfora", el narrador experimenta con una forma, sí, la forma trazada por la "Rosa del Caballo", trazo de ajedrez que nunca aparece en la obra de la estadounidense Katherine Neville, The Eight (1988), y el dato es ofrecido como hilarante broma por parte del autor. Pues bien, es un trazo en el tablero, de manera tal que el caballo pueda pasar por los 64 escaques sin repetir en ninguno. Advierte el autor:

Un aspecto que mixtura lo bello y lo misterioso es, a no dudarlo, el hecho de que al tomar un lápiz y trazar la ruta mediante líneas rectas que unan los centros de las casillas por donde pasa el caballo, resulta al cabo una rosa, si se la mira con ensueño ("Metáfora", 2013, p. 3).

Es decir, el entramado de estas guirnaldas son justamente las formas que nacen de la unión de los diferentes tropos literarios. Me atrevo a sugerir entonces que es la metáfora dentro de la metáfora, la literaturización del discurso metafórico por medio de un prisma que lo descompone en seis líneas: verde, roja, amarilla, azul, marrón y rosa.

1 Dimitri Shiltagh es Máster en Literatura, graduado de la Universidad de Costa Rica, y docente de la Escuela de Ciencias del Lenguaje del Instituto Tecnológico de Costa Rica. Contacto: dshiltagh@itcr.ac.cr.
Dimitri Shiltagh Prada. Un ensayo para una novela: Guirnaldas (Bajo tierra), de Rodolfo Arias: De la novela al discurso de la Academia Costarricense de la Lengua Española. Revista Comunicación. Año 37, volumen 25, número 2, julio - diciembre, 2016. Instituto Tecnológico de Costa Rica. ISSN: 0379-3974 / e-ISSN1659-3820. 
Lo explicado muestra la estructura de la novela tal como se presenta a los ojos del lector, y es este lector quien asume la postura del caballo y deja en su estela esa rosa, el lector queda invitado entonces a discurrir por el texto-tablero en un orden que le permitirá pasar por cada estación para la cual tiene su mapa adjunto a la novela.

El mapa de la novela es un boleto para el lector que comienza su recorrido en Barrio Córdoba; es el tiquete que lo llevará seguro por un mundo narrado con locuacidad. Quienes hemos leído otras obras de Rodolfo Arias, podemos decir que narra como si él mismo hubiera inventado la jerga.

El recorrido es prolijo en acontecimientos, pero está marcado por una ruta: este libro no es muchos libros, es uno solo, podría prefigurarse como un laberinto, pero solo eso; ya que el lector deja trazada una ruta, una ruta única e inalterable, cualquier variación podría dejarnos fuera de la partida o perdidos en el texto, queda a decisión del lector si prueba una ruta distinta a coste de perderse en la fractalidad bajo tierra. A lo mejor, los lectores podríamos caernos del tablero, si es que de metáfora está hecha la novela.

Planteo que es una novela fractal no solo por su forma, como ya hemos visto, sino también porque las intersecciones de las líneas plantean partes de un todo indivisible, separar cualquier parte resulta tan absurdo como si tratáramos de ver en esta novela solo una balumba, persiste y se antepone una lógica unida a la matemática. Cuando hemos entendido este episteme entraremos en una conexión permanente con el narrador, ya desde el principio nos encontramos frente al tablero que supone el texto de la novela, tablero que también encuentra su propia metáfora en la sala de teselación, línea amarilla 1; donde encontramos a Genia (hipocorístico de Ifigenia), quien es una niña genio, un personaje calamburesco, con el perdón del término si es que lo acuño.

El caso de Génesis Ifigenia (nótese el primer nombre como el origen, al final sabremos porqué, por irónico que parezca) merece especial atención, tal vez es el ejemplo más claro del estilo que permea todo el texto de la novela, como bien ha mencionado Sergio Arroyo en su página web denominada
"Cenizas de Ornitorrinco"1: "texto y tejido comparten etimología", el narrador enuncia un personaje al principio, en un espacio y al final lo retoma para colocarlo en un acontecimiento.

La sala de teselación es una clara advertencia sobre ese tejido, cuando el lector llega a esta sala por medio de la voz del narrador se encuentra con la metáfora de la metáfora: el tablero, es decir, una metáfora dentro de otra metáfora, como decir un pétalo dentro de otros pétalos, como se forma la rosa, "si se la mira con ensueño" ("Metáfora", 2013, p. 3).

En un orden paralelo, el 28 de abril de 2016, Rodolfo Arias recibía el premio de la Academia Costarricense de la lengua e hizo referencia a la frase de Borges cuando se le preguntó sobre su obra y sobre sí mismo. Decía Borges: "yo empecé, como todos los escritores, siendo un genio; y terminé siendo Borges". Pues bien, en el caso que nos ocupa, más bien esto se invierte (no debería sorprendernos una inversión tratándose de Rodolfo), pues Arias Formoso comienza siendo un pequeño genio con El Emperador Tertuliano y la Legión de los Superlimpios, sin embargo, eso que en literatura hemos Ilamado el genio creador, se ha vuelto más grande, más maduro y más intenso en su narrativa.

Guirnaldas (Bajo tierra) es una obra de madurez, según el mismo autor esta fue escrita entre 2009 y 2013, ¡vaya que fueron años de trabajo!, pues la obra que nos convoca es un texto finamente tejido, de ello da cuenta la forma en la cual van apareciendo los personajes, a amanera de puntadas que podríamos no entender, pero que poco a poco se devela como una obra cuyos acontecimientos están ancilados justamente a esos personajes. Los personajes, todos ellos muy bien configurados conforman ese único tablero sobre el cual se moverá el lector y dejará tras de sí esa rosa, en el afán inexcusable de saber y saber qué pasará. La hilaridad de esta novela confirma el estilo de este autor, pero esta vez el estilo aparece pulido, impecable: he ahí la madurez de la que escribo.

Llama la atención en el discurso de aceptación del premio una frase que bien vale para acuñar sobre ella mucha teoría literaria, ese germen del que vivimos filólogos, lectores y autores, nos dice Rodolfo:

\footnotetext{
1 Para más datos, consúltese la página http://sergioarroyo.com.
} 
Digo que la literatura es un puente de palabras, que en un extremo tiene el autor y su mundo, y en el otro al lector y el suyo. Y que la admiración y el cariño (o la repulsión y el encono) que carguen ese puente serán cosecha tanto del uno como del otro; fenómeno por el que vale en todo caso la pena apostar (Arias, 2016, p. 4).

Esta vez es un puente de cincuenta y cinco capítulos, tendidos cada uno para que el lector pase sobre ellos y descubra, se enoje, dialogue o cuestione a ese narrador que se yergue en el relato como un guardián del espíritu de la obra. Palabras que cuentan una novela que se descompone en subnovelas, dentro de las cuales hay, en cada una "subnovelita", me decía el autor cuando chateamos por primera vez al respecto de esta obra.

Prosiguiendo con las palabras del discurso de aceptación del premio, hay un punto en el que quiero detenerme, esta es la pregunta: “¿Qué quiere decir que un objeto sea fractal?". Curiosa pregunta, pues antes de conocer este discurso ya había puesto título a este ensayo, en el cual me refería a la fractalidad, pensando además en el tema de la matemática tan acendrado en el relato. Hemos de coincidir entonces que si bien, como mencioné, fortuna y juego son esenciales para esta novela como concreción de la metáfora, la realidad que permea este texto está dada por otro binomio del mundo real: la matemática y la esencia del todo en la parte, como decir sinécdoque, como puliendo las bases del andamiaje, eso que llamamos tropos. Ambos binomios se presentan como reflejo el uno del otro, y si se trata de una novela de este autor también diremos: el otro del uno, pues esa indivisibilidad del todo podría solo explicarse en la fractalidad, en el aspecto matemático y no por las facultades naturales de percepción de las que pudiera valerse el lector, pues el mismo autor así lo quiso, buscando precisamente "que fuera una novela en cada una de sus partes". Por ejemplo, si Clifford Hebden no se encuentra el "queso" flotando, posiblemente Wolfgang se habría fugado, y posiblemente Manuel no se habría suicidado. Y así para todo: cualquier personaje es el "culpable" de toda la historia, pues lleva en su parte la esencia del todo.
¿Se trata de una novela recursiva?, sí, lo es; su mismo autor nos dice en su discurso de aceptación del premio de la Academia Costarricense de la Lengua:

Yo quería una novela recursiva. Y para esto necesitaba un narrador, digámoslo así, "supra-omnisciente" que conociera no sólo los ejes² del primer plano del relato, sino los que estarían en un segundo nivel, en un tercero y así sucesivamente. Un narrador que sostuviera las invocaciones requeridas para pasar de un piso al próximo, dando por ende soporte al edificio completo de causas y efectos (Arias, 2016, p. 5).

Quisiera, a fuerza de no "filologar", plantear que como arguyó Eagleton en 1983: "En caso de que exista algo que pueda denominarse teoría literaria, resulta obvio que hay una cosa que se denomina literatura sobre la cual teoriza" (p. 9), Guirnaldas (Bajo tierra) trae consigo un hálito de libertad para el lector crítico: las conexiones entre el ser humano, su destino y el mundo. Bien concibió Eagleton este concepto, pues en Guirnaldas (Bajo tierra) ¿qué teoría literaria cabría?

Tendríamos que sentarnos, filólogos y críticos, a dialogar en una suerte de onanismo psíquico para crear el eterno juego peligroso: buscar la teoría que mejor se ajuste al texto, como buscar la aguja con el ojo preciso por donde pase el hilo con exactitud, si es que de un tejido literario hablamos; pero no tendríamos resultados absolutos, de esos que nos permiten fijar la novela en un punto de donde no se moverá nunca más, no podríamos petrificarla: la prosa de Arias Formoso escapa a ello y se sitúa allá donde el lector y su deleite pueden más que tropos, hiperbatones, sinestesias, calambures y ... "carambadas".

El estilo trabajado y pulido de Rodolfo Arias pone en su escrito el símbolo de una relación del destino y este determina la forma. Toda escritura textual, novelada o tejida como Guirnaldas (Bajo tierra), es una aspiración a la multiplicidad de las cosas, nos recuerda Lukács (1920), y es la articulación en la masa de una sola materia la que se vuelve viable en esta novela, pero podría no serlo en otra prosa , en otro estilo, en otro escritor.

Finalmente, este libro no es muchos libros, pero sí es muchas formas, y podría ser muchas novelas porque su fractalidad y recursión así lo permiten, pero esas

2 Personajes, acontecimientos, tiempo, espacio... 
forman asisten a ser leídas, interpretadas, a no dejarse anclar filológicamente porque lo que no es laberinto lo parece y en virtud de la verosimilitud podríamos preguntarnos incluso si existe la literatura. La respuesta es sí y Guirnaldas (Bajo tierra) es muestra de ello.

\section{REFERENCIAS BIBLIOGRÁFICAS}

Arias, R. (1991). El emperador Tertuliano y la legión de los superlimpios. San José: EDUCA.
Arias, R. (2013). Guirnaldas (bajo tierra). Costa Rica: Editorial Lanzallamas.

Arroyo, S. (2013). Cenizas de Ornitorrinco. Descargado desde http://sergioarroyo.com el_14 de julio de 2016.

Eagleton, T. (1998). Las ilusiones del posmodernismo. Buenos Aires: Editorial Paidós.

Lukács, G. (1920). Die Theorie des Romans. Alemania: Gutemberg.

Neville, K. (1988). The eight. Estados Unidos: New York City. 